\title{
MOSQUITO REPELLENT ACTION OF DURANTA PLUMIERI (VERBENACEAE) AGAINST CULEX QUINQUEFASCIATUS
}

\author{
PAYAL MITTAL ${ }^{1 *}$, MANISH GOSWAMI ${ }^{1}$, MONIKA AIRI ${ }^{2}$
}

${ }^{1}$ Department of Pharmacology, University Institute of Pharma Sciences, Chandigarh University, Mohali, Punjab, India. ${ }^{2}$ Department of Zoology, Sri Guru Granth Sahib World University, Fatehgarh Sahib, Punjab, India. Email: payal_mittal84@yahoo.com

Received: 08 March 2019, Revised and Accepted: 15 May 2019

\section{ABSTRACT}

Objective: The objective of the study was to investigate the repellent activity of different extracts of Duranta plumieri against mosquito vector Culex quinquefasciatus.

Methods: Four different extracts (petroleum ether, chloroform, ethanol, and aqueous) of D. plumieri were evaluated for repellency test against mosquito vector $C$. quinquefasciatus Say (Diptera: Culicidae) in comparison with diethyltoluamide (DEET), which was used as a positive control.

Results: Results showed that chloroform extract was the most effective against mosquito vector even at a low dose. A direct relationship was observed with different concentrations of $D$. plumieri extract and the repellent activity. Moreover, all the extracts showed highly significant level of repellency as compared to DEET at $10 \%$ dosage till $5 \mathrm{~h}$ of exposure. Among all of these, chloroform extract showed significant repellency at $5 \%$ dosage till $4 \mathrm{~h}$.

Conclusion: Chloroform extract of $D$. plumieri has the potential as an effective mosquito repellent and further studies are needed to isolate the marker compound responsible for this activity.

Keywords: Duranta plumieri, Culex quinquefasciatus, Mosquito repellent.

(C) 2019 The Authors. Published by Innovare Academic Sciences Pvt Ltd. This is an open access article under the CC BY license (http://creativecommons. org/licenses/by/4. 0/) DOI: http://dx.doi.org/10.22159/ajpcr.2019.v12i6.32981

\section{INTRODUCTION}

Mosquitoes cause major health hazards to human beings as they are the carrier of various deadly diseases [1]. Mosquitoes belong to the family Culicidae of order Diptera of class insecta and are characterized by their slender body, long legs, long proboscis, and scales on most of the body parts [2]. Anopheles, Culex, and Aedes are carriers for transmitting a number of diseases such as dengue fever, malaria, filariasis, dengue hemorrhagic fever, Japanese encephalitis, chikungunya, and yellow fever [3]. A large number of the population is at risk due to these mosquito-borne diseases [4].

Human mosquito contact has to be prevented to protect from mosquitoborne diseases. Insect repellents such as tars, smokes, plant oils, and other modalities have been used since ancient times [5]. At present, new synthetic repellents have been developed by different researchers. However, these synthetic repellents have many unfavorable side effects [6]. The problems associated with the use of chemical repellents can be overcome using herbal products. Plant products have been used by our ancestors to repel or kill the insects. Many plants have been proved as potential insect repellents [7-9]. Commercially used repellents in the market are citronella and diethyltoluamide (DEET) [10]. Although DEET is the most commonly used repellent, different communities use several plants in various forms to protect themselves from insect bites [10-12]. Therefore, the need is to discover a safe and economical repellent. Considering the price, investigation on the use of regional plants as repellents is strongly endorsed [10]. Citronella and quelling (a waste distillate of lemon eucalyptus) are available on a large scale [10]. A formulation prepared from lemon eucalyptus has been used commercially in the UK [13]. Cotton fabric coated with lemon grass extract capsule mixture showed good mosquito repellent activity [14]. Many essential oils have proven mosquitocidal activity [15]. Extracts of Duranta plumieri Linn (Verbenaceae) showed antifeedant and insecticidal effect against the larvae of Culex pipiens Linn and Spodoptera littoralis Boised as well as against the adults of Musca domestica Linn (Muscidae) and $C$. pipiens, respectively [16]. Leaf extract of Lantana indica and vitex proved good repellent action on Culex species [17]. Leaf and fruit extract of Gardenia gummifera exhibited good larvicidal and pupicidal activity against Aedes aegypti [18] D. plumieri fruits were screened for antimalarial activity through oral and subcutaneous routes on mice infected with Plasmodium berghei Anka (Plasmodiidae) [16]. D. plumieri chloroform extract of fruits proved to have antifeedant activity against Heliothis armigera Hubner (Reoviridae) [18]. D. plumieri aerial parts exhibited antiviral activity against Hepatitis A virus [19-21]. Hence, keeping in view the above-mentioned insecticidal and viricidal properties of D. plumieri, the present study was designed to evaluate its repellent activity against mosquitoes, especially Culex quinquefasciatus.

\section{METHODS}

Plant material collection

D. plumieri leaves were collected from Fathepur, Distt Kangra, Himachal Pradesh and were identified taxonomically by Kumar Ambrish, Scientist, Botanical Survey of India, Dehradun, having Authentication Voucher no. 118055. The leaves were cleaned with tap water and then rinsed in distilled water. Next, these were shade dried and stored in air tight container for future use.

\section{Extraction of $D$. plumieri}

D. plumieri leaves were coarsely powdered and subjected to extraction through cold maceration. Powder of 100 gm leaves was kept in a round bottom flask and solvents petroleum ether, chloroform, ethanol, and water were added successively for $48 \mathrm{~h}$ and then filtered with muslin cloth. The filtered extract of various solvents was concentrated using rotary evaporator and dried in hot air-oven below $50^{\circ} \mathrm{C}$. The dried extracts were stored in a corked bottle and refrigerated.

\section{Mosquito strains}

Larvae of $C$. quinquefasciatus were collected from Gharuan village of Mohali and were reared in a room with a constant temperature $\left(27 \pm 2^{\circ} \mathrm{C}\right)$ and relative humidity $(70 \%)$ along with a photoperiod of 
12 h (Light: Dark). Adult mosquitoes were fed with 10\% sucrose. Adult mosquitoes were kept in mosquito cages and starved for overnight. Triplicates were prepared.

\section{Repellent and control preparation}

Repellent surface was prepared in a $6 \mathrm{~cm}$ diameter plastic bowl. Cotton was placed in adequate quantity in $250 \mathrm{ml}$ plastic bowl. $10 \%$ solution of sugar was prepared in distilled water and cotton was soaked by pouring $230 \mathrm{ml}$ of sugar solution into the plastic bowl. Top layer of cotton at the top was covered with a single layer of nylon net. In the remaining $20 \mathrm{ml}$, different concentrations of repellent were prepared. Different concentrations of extract, namely $2.5,5$, and 10 were prepared by mixing $20 \mathrm{ml}$ of sugar solution with the required quantity of extract and were poured evenly on the sugar soaked cotton in the above plastic bowl. In the same manner, $2 \%$ solution of DEET was prepared in $10 \%$ sugar soaked cotton for use as positive control and only $10 \%$ sugar soaked cotton was used as a negative control, respectively. Various test concentrations, namely $2.5,5,10$, and $10 \%$ were prepared in distilled water using freshly made stock solution.

\section{Repellency test}

The repellency test was carried out in a room maintained at $27^{\circ} \mathrm{C}$ and $70 \%$ relative humidity. The mosquitoes along with cages were kept in the room. The plastic bowl containing cotton soaked in three different concentrations of extract of D. plumieri, namely $2.5,5,10$, and $10 \%$ solution of sugar, DEET 2\% (positive control) in 10\% solution of sugar and $10 \%$ solution of sugar (negative control) were placed in four different corners and one in the center of the cage. Landing counts for 5 min were made at each hour for $6 \mathrm{~h}(0,1,2,3,4,5$, and $6 \mathrm{~h})$. After observation of $5 \mathrm{~min}$, the bowls were removed from the cage at each interval of time. To avoid evaporation, the bowl was covered and kept in the refrigerator. The position of bowels was interchanged for subsequent exposure.

\section{Data analysis}

Observations for mosquito cage studies were made with triplicates for the selected species of the mosquito. Rates of the mosquito landing on the treated bowls with different concentrations of the extract of D. plumieri $2.5,5,10$, and $10 \%$, DEET $2 \%$ and sugar $(10 \%)$ were noted. Mean of the observations for was recorded for each. Results were expressed as average landing and percent repellency per exposure interval compared to control using the following formula [22].

$$
\text { Percent repellency }=\text { Control }(C)-\text { Treatment }(T) / \text { Control }(C) \times 100
$$

Where, $\mathrm{C}=$ The mean number of landing on negative control $(10 \%$ sugar solution); $\mathrm{T}=$ Mean number of landing on the repellents (DEET and extract of $D$. plumieri)

\section{Statistical analysis}

For evaluating the significant difference between the repellent activity of DEET and different extracts of $D$. plumieri at different concentrations, Student's t-test was applied where $\mathrm{p}<0.05$ was considered as the significant value.

\section{RESULTS}

The leaf extract of $D$. plumieri exhibited strong repellent activity against $C$. quinquefasciatus. There is a great difference between the mean number of mosquitoes landing on the control and the treated surfaces (Tables 1-4). The percent repellency of chloroform extract was maximum and varied from 90 to $69 \%$ against different concentrations at different observation periods ( $0 \mathrm{~h}, 1 \mathrm{~h}, 2 \mathrm{~h}, 3 \mathrm{~h}, 4 \mathrm{~h}, 5 \mathrm{~h}$, and $6 \mathrm{~h})$. The repellency rates at $0 \mathrm{~h}$ varied between 86 and $90 \%$ at different concentrations of $D$. plumieri extract. Petroleum ether, ethanol, and aqueous extracts also showed mosquito repellent activity but lesser than chloroform extract. Moreover, all the extracts showed a highly

Table 1: Percent repellency of petroleum ether extract of leaf of Duranta plumieri against Culex quinquefasciatus

\begin{tabular}{|c|c|c|c|c|c|c|c|c|}
\hline \multirow[t]{2}{*}{ Species } & \multirow[t]{2}{*}{ Doses (\%) } & \multicolumn{7}{|c|}{ Repellency in h (Mean \pm SEM) } \\
\hline & & $\mathbf{O h}$ & 1 & 2 & 3 & 4 & 5 & 6 \\
\hline \multirow[t]{4}{*}{ Culex quinquefasciatus } & 2.5 & $84.66 \pm 0.33$ & $85.33 \pm 0.33^{* *}$ & $84.66 \pm 0.88$ & $72.66 \pm 1.20^{* *}$ & $73.00 \pm 1.00^{* *}$ & $69.66 \pm 1.20$ & $68.33 \pm 0.33$ \\
\hline & 10 & $89.66 \pm 1.20^{* *}$ & $86.66 \pm 1.33^{* *}$ & $85.66 \pm 0.33^{* *}$ & $74.00 \pm 1.52^{* *}$ & $74.33 \pm 1.20^{* *}$ & $72 \pm 1.73^{* *}$ & $67.66 \pm 0.88$ \\
\hline & DEET & $95.66 \pm 0.33$ & $96.66 \pm 0.33$ & $97.33 \pm 0.33$ & $98.33 \pm 1.20$ & $93.66 \pm 0.88$ & $92.66 \pm 0.33$ & $90.33 \pm 0.33$ \\
\hline & Sucrose & $9.66 \pm 1.85$ & $6.33 \pm 1.85$ & $8.66 \pm 0.33$ & $7.33 \pm 1.33$ & $7.33 \pm 0.33$ & $8.33 \pm 0.88$ & $8.33 \pm 2.02$ \\
\hline
\end{tabular}

${ }^{*} \mathrm{p}<0.05$ significant, ${ }^{* *} \mathrm{p}<0.001$ highly significant, SEM: Standard error of the mean, DEET: Diethyltoluamide

Table 2: Percent repellency of chloroform extract of leaf of Duranta plumieri against Culex quinquefasciatus

\begin{tabular}{|c|c|c|c|c|c|c|c|c|}
\hline \multirow[t]{2}{*}{ Species } & \multirow[t]{2}{*}{ Doses (\%) } & \multicolumn{7}{|c|}{ Repellency in h (Mean \pm SEM) } \\
\hline & & $\mathbf{O} \mathbf{h}$ & 1 & 2 & 3 & 4 & 5 & 6 \\
\hline \multirow[t]{5}{*}{ Culex quinquefasciatus } & 2.5 & $86.66 \pm 0.33$ & $86.66 \pm 0.66^{*}$ & $85.33 \pm 1.45^{* *}$ & $74.33 \pm 2.40^{* *}$ & $76 \pm 1.52^{* *}$ & $72.33 \pm 0.33$ & $70.33 \pm 1.33$ \\
\hline & 5 & $87 \pm 0.58^{* *}$ & $87.66 \pm 0.66^{* *}$ & $86 \pm 1.52^{* *}$ & $77.33 \pm 1.20^{* *}$ & $74.33 \pm 0.66^{* *}$ & $70.33 \pm 0.33$ & $68.66 \pm 0.33$ \\
\hline & 10 & $89.33 \pm 1.33^{* *}$ & $86.66 \pm 0.88^{* *}$ & $87 \pm 0.57^{* *}$ & $74.33 \pm 1.20^{* *}$ & $74 \pm 1.52^{* *}$ & $73.33 \pm 1.33^{* *}$ & $69.33 \pm 1.52^{* *}$ \\
\hline & DEET & $95.66 \pm 0.33$ & $96.66 \pm 0.33$ & $97.33 \pm 0.33$ & $98.33 \pm 1.20$ & $93.66 \pm 0.88$ & $92.66 \pm 0.33$ & $90.33 \pm 0.33$ \\
\hline & Sucrose & $9.66 \pm 1.85$ & $6.33 \pm 1.85$ & $8.66 \pm 0.33$ & $7.33 \pm 1.33$ & $7.33 \pm 0.33$ & $8.33 \pm 0.88$ & $8.33 \pm 2.02$ \\
\hline
\end{tabular}

$* \mathrm{p}<0.05$ significant, $* * \mathrm{p}<0.001$ highly significant, SEM: Standard error of the mean, DEET: Diethyltoluamide

Table 3: Percent repellency of the ethanol extract of leaf of Duranta plumieri against Culex quinquefasciatus

\begin{tabular}{|c|c|c|c|c|c|c|c|c|}
\hline \multirow[t]{2}{*}{ Species } & \multirow[t]{2}{*}{ Doses (\%) } & \multicolumn{7}{|c|}{ Repellency in h (Mean \pm SEM) } \\
\hline & & $\mathbf{O} \mathbf{h}$ & 1 & 2 & 3 & 4 & 5 & 6 \\
\hline \multirow[t]{5}{*}{ Culex quinquefasciatus } & 2.5 & $79.66 \pm 1.20^{* *}$ & $78.66 \pm 2.02^{* *}$ & $75.66 \pm 0.33$ & $71.66 \pm 2.18$ & $68.33 \pm 0.33$ & $66.66 \pm 0.88$ & $59.66 \pm 1.20$ \\
\hline & 5 & $83.66 \pm 0.33$ & $82 \pm 0.57$ & $77.66 \pm 0.88$ & $71.66 \pm 0.33$ & $68.66 \pm 0.33$ & $69 \pm 2.08$ & $62.33 \pm 1.20$ \\
\hline & 10 & $83.66 \pm 1.66^{* *}$ & $82.66 \pm 1.76^{* *}$ & $82.33 \pm 2.84^{*}$ & $72 \pm 3.51^{* *}$ & $73.66 \pm 2.72^{* *}$ & $68.33 \pm 2.02^{* *}$ & $63 \pm 0.57$ \\
\hline & DEET & $95.66 \pm 0.33$ & $96.66 \pm 0.33$ & $97.33 \pm 0.33$ & $98.33 \pm 1.20$ & $93.66 \pm 0.88$ & $92.66 \pm 0.33$ & $90.33 \pm 0.33$ \\
\hline & Sucrose & $9.66 \pm 1.85$ & $6.33 \pm 1.85$ & $8.66 \pm 0.33$ & $7.33 \pm 1.33$ & $7.33 \pm 0.33$ & $8.33 \pm 0.88$ & $8.33 \pm 2.02$ \\
\hline
\end{tabular}

${ }^{*} \mathrm{p}<0.05$ significant, ${ }^{* *} \mathrm{p}<0.001$ highly significant, SEM: Standard error of the mean, DEET: Diethyltoluamide 
Table 4: Percent repellency of the aqueous extract of leaf of Duranta plumieri against Culex quinquefasciatus

\begin{tabular}{|c|c|c|c|c|c|c|c|c|}
\hline \multirow[t]{2}{*}{ Species } & \multirow[t]{2}{*}{ Doses (\%) } & \multicolumn{7}{|c|}{ Repellency in h (Mean \pm SEM) } \\
\hline & & $\mathbf{O} \mathbf{h}$ & 1 & 2 & 3 & 4 & 5 & 6 \\
\hline \multirow[t]{4}{*}{ Culex quinquefasciatus } & 2.5 & $75.66 \pm 1.76^{* *}$ & $74.66 \pm 0.88$ & $74 \pm 2.00$ & $70.66 \pm 0.33$ & $66.66 \pm 0.88$ & $65.66 \pm 1.20$ & $56.33 \pm 1.33$ \\
\hline & 10 & $81.66 \pm 0.88^{* *}$ & $81.33 \pm 1.85^{* *}$ & $80.66 \pm 2.18^{* *}$ & $72.66 \pm 2.33^{* *}$ & $69 \pm 0.57^{* *}$ & $68 \pm 0.57$ & $63.33 \pm 1.20$ \\
\hline & DEET & $95.66 \pm 0.33$ & $96.66 \pm 0.33$ & $97.33 \pm 0.33$ & $98.33 \pm 1.20$ & $93.66 \pm 0.88$ & $92.66 \pm 0.33$ & $90.33 \pm 0.33$ \\
\hline & Sucrose & $9.66 \pm 1.85$ & $6.33 \pm 1.85$ & $8.66 \pm 0.33$ & $7.33 \pm 1.33$ & $7.33 \pm 0.33$ & $8.33 \pm 0.88$ & $8.33 \pm 2.02$ \\
\hline
\end{tabular}

${ }^{*} \mathrm{p}<0.05$ significant, ${ }^{* *} \mathrm{p}<0.001$ highly significant, SEM: Standard error of the mean, DEET: Diethyltoluamide

significant level of repellency as compared to DEET at 10\% dosage till $5 \mathrm{~h}$ of exposure. Among all of these, chloroform extract showed significant repellency at $5 \%$ dosage till $4 \mathrm{~h}$.

\section{DISCUSSION}

Chloroform leaf extract of $D$. plumieri showed up to $90 \%$ repellency against $C$. quinquefasciatus in laboratory bioassays. These results show that $D$. plumieri chloroform leaf extract is potentially an effective mosquito repellent. The efficacy of $D$. plumieri leaf extract is comparable with the currently used commercial repellent product DEET. Although DEET provided better and longer protection, it has certain health risks that should be considered while using it [23]. Nowadays, trend for the use of natural repellent products is gaining importance and several botanicals have been screened for mosquito repellent activity [24-27]. The petroleum ether extract ofJusticia adhatoda showed mosquito strong repellent action as it gave $100 \%$ protection against $C$ quinquefasciatus $180 \mathrm{~min}$ followed by A. aegypti for $210 \mathrm{~min}$ [28]. Andrographis paniculata ethanol extract proved mosquitocidal activity of $94.2 \%$ of mortality at $3.0 \mathrm{mg} / \mathrm{cm}^{2}$ [29]. The methanol extract of Eclipta alba and A. paniculata produced maximum repellent effect against Anopheles Stephensi [30]. The maximum repellent activity was observed at $500 \mathrm{ppm}$ in the methanol extracts of Aegle marmelos, Acacia lineata, and ethyl acetate extract of Chamaecytisus hirsutus, and the mean complete protection time ranged from 90 to 120 min against Anopheles subpictus. The hexane extract of $A$. paniculata showed a better mosquito repellent effect in comparison with Acacia lineate extract [31]. Neem oil showed $37.5 \%$ protection against $C$. quinquefasciatus, whereas, in the present study, the chloroform leaf extract of D. plumieri showed up to $90 \%$ repellency against the same species, but the efficacy declined after $2 \mathrm{~h}$. Most of the plant-based repellents are shown to repel mosquitoes, but for short duration (few minutes to some hours). Most of the phytoconstituents are volatile; therefore, they provide repellent effect for a short duration after application and rapidly evaporate leaving the user unprotected [24]. Para-menthane 3, 8 diol, a herbal repellent extracted from the leaves of lemon eucalyptus Corymbia citriodora (Myrtaceae) tree is an exception, which is less volatile than monoterpenes and provides effective repellency against a large number of insect vectors for several hours and it has been advised for use in disease-endemic areas by the Centers For Disease Control as it considered safe for human health [24]. More research is needed to develop new repellents from the substance of herbal origin that can provide effective mosquito control to reduce the indiscriminate use of a harmful chemical insecticide. Although the outcomes of the present study showed the potential of D. plumieri extracts mosquito repellent against $C$. quinquefasciatus in laboratory bioassays, these results are applicable in cage experiments at laboratory level that involves sugar solution as attractant; therefore, confirmation is needed by testing it on human volunteers, and further experimentation should be undertaken against other mosquito vectors under field and laboratory conditions.

\section{CONFLICTS OF INTEREST}

Nil.

\section{AUTHORS' CONTRIBUTIONS}

This work was carried out in collaboration between all authors. Authors PM, MG, and MA designed the experiments and wrote the first draft of the manuscript. Authors PM and MA performed all the scientific experiments and typed the manuscript. All authors read and approved the final manuscript.

\section{REFERENCES}

1. El-Hag EA, El-Nadi AH, Zaitoon AA. Toxic and growth retarding effects of three plant extracts on Culex pipiens larvae (Diptera: Culicidae). Phyther Res 1999;13:388-92.

2. Barraud PJ. The Fauna of British India, Including Ceylon and Burma. Diptera. Vol. 5. Family Culicidae. Tribes Megarhinini and Culicini. London: Taylor and Francis; 1934. p. 1-463.

3. Hubálek Z, Halouzka J. West nile fever a reemerging mosquito-borne viral disease in europe. Emerg Infect Dis 1999;5:643-50.

4. Service MW. Mosquitoes (Culicidae). London: Chapman and Hall; 1993.

5. Peterson C, Coats J. Insect repellents-past, present and future. Pestic Outlook 2001;12:154-8.

6. Mandal S. Repellent activity of Eucalyptus and Azadirachta indica seed oil against the filarial mosquito Culex quinquefasciatus Say (Diptera: Culicidae) in India. Asian Pac J Trop Biomed 2011;1:109-12.

7. King WV. Chemicals Evaluated as Insecticides and Repellents at Orlando, Florida, Agricultural Handbook No. 69. Washington, D.C: U.S. Department of Agriculture; 1954

8. Jacobson M. Glossary of Plant Derived Insect Deterrents. Boca Raton: CRC press; 1990.

9. Sukumar K, Perich MJ, Boober LR. Botanical derivatives in mosquito control: A review. J Am Mosq Control Assoc 1991;30:122-4.

10. Curtis CF, Lines JD, Lu B, Renz A. Natural and synthetic repellents. In: Curtis CF, editor. Appropriate Technology in Vector Control. Boca Raton, CRC Press; 1990. p. 75-92.

11. Hebbalkar DS, Hebbalkar GD, Sharma RN, Joshi VS, Bhat VS. Mosquito repellent activity of oils from Vitex negundo Linn. Leaves. Indian J Med Res 1992;95:200-3

12. White GB. The insect-repellent value of Ocimum spp. (Labiatae): Traditional anti-mosquito plants. East Afr Med J 1973;50:248-52.

13. Trigg JK, Hill N. Laboratory evaluation of a eucalyptus based repellent against four biting arthropods. Phytother Res 1996;10:313-6.

14. Vinayagamoorthy P, Senthilkumar B, Patchiyappan KM, Kavitha R. Microencapsulated lemongrass oil for mosquito repellent finishing of knitted cotton wear. Asian J Pharm Clin Res 2017;10:303-7.

15. Ramar M, Ignacimuthu S, Manonmani P, Murugan K. Adulticidal activity of botanical oils by impregnated paper assay against Culex quinquefasciatus Say. Int J Pharm Pharm Sci 2017;9:156-60.

16. El-Naggar ME, Mosallam SS. Insecticidal properties of some isolates from Duranta repens L. J Egypt Soc Parasitol 1987;17:243-9.

17. Rathnasagar K, Thiyagaraj A. Larvicidal activity of Lantana Indica and Vitex negundo on Culex quinquefasciatus. Asian J Pharm Clin Res 2018;11:414-8.

18. Kekuda TR, Raghavendra HL, Shilpa M, Pushpavathi D, Petkar T, Siddiqha A. Antimicrobial, antiradical and insecticidal activity of Gardenia gummifera L. F. (Rubiaceae). Int J Pharm Pharm Sci 2017;9:265-72.

19. Castro O, Barrios M, Chinchilla M, Guerrero O. Chemical and biological evaluation of the effect of plant extracts against Plasmodium berghei. Rev Biol Trop 1996;44:361-7.

20. Patil VJ, Deshmukh MB, Maner MI. Antimicrobial and antifeedant activity of the extract of the plant Duranta repens. J Biotech Agric Ind Environ 2002;5:65-7.

21. Lobna MA, Naglaa MN, Abdellaaty AS. Phytochemical investigation and antiviral activity of Duranta repens. J Appl Sci Res 2007;3:1426-33.

22. Ansari MA, Vasudevan P, Tandon M, Razdan RK. Larvicidal and mosquito repellent action of peppermint (Mentha piperita) oil. 
Bioresource Tech 2000;71:267-71.

23. Qiu H, Jun WM. Pharmacokinetic, formulation and safety of insect repellent N, N-diethyl-3-methylbenzamide (DEET): A review. J Am Mosq Control Assoc 1998;14:12-27.

24. Maia MF, Moore SJ. Plant-based insect repellents: A review of their efficacy, development and testing. Malar J 2011;10 Suppl 1:11.

25. Novak RJ, Gerberg EJ. Natural-based repellent products: Efficacy for military and general public users. J Am Mosq Control Assoc 2005;21:7-11.

26. Pålsson K, Jaenson TG. Plant products used as mosquito repellents in Guinea Bissau, West Africa. Acta Trop 1999;72:39-52.

27. Tuetun B, Choochote W, Rattanachanpichai E, Chaithong U, Jitpakdi A, Tippawangkosol P, et al. Mosquito repellency of the seeds of celery Apium graveolens L. Ann Trop Med Parasitol 2004;98:407-17.
28. Jayapriya G, Shoba FG. Larvicidal, ovicidal, adulticidal and repellent activity of Justicia adhatoda Linn (Acanthaceae) against Aedes aegypti Linn and Culex quinquefasciatus Say. Int J Rec Sci Res 2014;5:2321-7.

29. Kuppusamy C, Murugan K. Mosquitocidal effect of Andrographis paniculata Nees against the malarial vector, Anopheles stephensi Liston (Diptera: culicidae). Int J Intergrative Biol 2009;5:75-81.

30. Govindarajan M, Sivakumar R. Mosquito adulticidal and repellent activities of botanical extracts against malarial vector, Anopheles stephensi Liston (Diptera: Culicidae): Asian Pac J Trop Med 2011;4:941-7.

31. Elango G, Rahuman AA, Bagavan A, Kamaraj C, Zahir AA, Rajakumar G, et al. Efficacy of botanical extracts against Japanese encephalitis vector Culex tritaeniorhynchus. Parasitol Res 2010;106:481-92. 